論文

\author{
철도차량 대차 적용 유리섬유/에폭시 4-매 주자직 적층 복합재의 \\ 인장-압축 피로특성 평가 연구 \\ 전광우, 신광복 ${ }^{* *+}$, 김정석 ${ }^{* * *}$
}

\title{
A Study on the Evaluation of Tension-Compression Fatigue Characteristics of Glass Fiber/Epoxy 4-Hamess Satin Woven Laminate Composite for the Railway Bogie Application
}

\author{
Kwang-Woo Jeon ${ }^{*}$ Kwang-Bok Shin ${ }^{* *+}$ and Jung-Seok Kim ${ }^{* * *}$
}

\begin{abstract}
This paper describes the evaluations of tension-compression fatigue characteristics and life for glass fiber/epoxy laminate composite applied to railway bogie to reduce weight. Test samples of tension-compression fatigue were composed of glass fiber/epoxy 4-harness woven laminate composites with different stacking sequence of warp-direction, fill-direction and $\pm 45^{\circ}$-direction. The tension-compression fatigue test was conducted with stress ratio (R) of -1 and frequency of $5 \mathrm{~Hz}$. Goodman diagram were used to evaluate the fatigue characteristics and life of glass fiber/epoxy 4-harness satin woven laminate composite. Anti-buckling jig was designed to prevent buckling of specimen under compression load. The test results showed that the fatigue characteristics of glass fiber/epoxy 4-harness satin woven laminate composite with stacking sequence of warp-direction had a good performance in comparison with that of SM490 used to conventional metal railway bogie.

\section{초 록}

본 논문은 철도차량 경량화 재질로 적용된 유리섬유/에폭시 4-매 주자직 적층 복합재료의 인장-압축 피로특성을 평가하였 다. 유리섬유/에폭시 4-매 주자직 적층 복합재료의 인장-압축 피로시험은 경사, 위사 그리고 $\pm 45^{\circ}$ 방향으로 적층된 시험편에 대하여 수행하였다. 인장-압축 피로시험은 $5 \mathrm{~Hz}$ 의 주파수를 갖으며, 응력비(R)는 -1로 수행하였다. 인장-압축 피로시험 수행 시 압축하중에 의한 시험편의 좌굴을 방지하기 위하여 좌굴방지지그를 설계하고 이를 시험에 적용하였다. 또한, Goodman 선도 는 유리섬유/에폭시 4-매 주자직 적층 복합재의 피로특성과 수명을 평가하기 위해 사용하였다. 유리섬유/에폭시 4-매 주자직 적층 복합재료의 인장-압축 피로시험결과 경사방향 적층 복합재의 피로특성이 기존 금속재 대차에 적용되는 SM490에 비하여 우수한 것으로 나타났다.
\end{abstract}

Key Words : 4-매 주자직(4-Harness satin woven), 인장-압축 피로(Tension-Compression fatigue), 복합재 대차프레임(Composite bogie frame), 좌굴방지지그(Anti-buckling jig)

* 한밭대학교, 기계설계공학과, 경량구조 및 $\mathrm{CAE}$ 실험실

**+한밭대학교, 기계설계공학과, 교신저자(E-mail:shin955@hanbat.ac.kr)

*** 한국철도기술연구원, 책임연구원 


\section{1. 서 론}

철도차량은 높은 단위 수송력 및 에너지 효율을 지니고 있 어 최근 친환경 지상운송수단으로 각광받고 있으며, 이를 극대 화하기 위한 경량화 연구가 활발히 진행되고 있다. 철도차량의 경량화는 운행속도의 향상과 에너지 효율 증가뿐만 아니라, 유 효 탑재량 증가, 유지보수 비용 저감 등의 파급효과를 얻을 수 있다[1-3]. 따라서, 철도차량의 경량화는 차량개발 단계에서 필 수적인 요구사항으로 받아들여지는 추세이다[4]. 철도차량의 보 편적인 경량화 방법으로는 기존 차량 구성 재질을 경량화 소재 로 대체하는 것이다[5]. 소재 대체를 통한 철도차량의 경량화는 1세대 차체 재료인 강재(steel) 및 스테인레스강(stainless steel) 으로부터 2세대 차체 재료인 알루미늄(aluminum)으로 경량화 하였으며, 최근 3세대 차체 재료인 복합재(composite)를 이용한 경량화 연구가 활발히 진행되고 있다[6-7]. 3세대 철도차량 재 료인 복합재료는 1990 년 후반부터 $100 \mathrm{~km} / \mathrm{h}$ 이하의 경량전철, 모 노레일 및 자기부상열차의 차체 구조물에 적용 되었으며, $180 \mathrm{~km} / \mathrm{h}$ 급 중고속열차의 경우 루프(roof), 사이드 구조(side structure)등에 제한적으로 적용되어 왔다[8-10]. 최근 국내에 서는 복합재를 차체 전체에 적용한 한국형 틸팅열차(TTX), 자동무인경전철(AGT) 그리고 바이모달 트램(Bimodal tram) 이 개발되어 시험운행 중에 있다[11-13].

그러나, 철도차량의 중량 중 많은 부분을 차지하는 대차프 레임의 경우 차체와 승객의 하중을 지지하는 특성으로 보수적 인 설계가 수행되어 왔으며[14-15], 국내의 경우 복합재 적용 대차프레임 경량화 연구가 전무한 실정이다. 복합재 적용 대 차프레임의 경량화 연구 사례로 2001년도에 프랑스의 알스톰 (Alstom)에서 개발된 $200 \mathrm{~km} / \mathrm{h}$ 급 TER 대차(TER bogie)에 부 분적으로 복합재가 적용되었으며, 기존 금속재 대차프레임에 비하여 $22 \%$ 이상의 경량화 효과를 얻었다[16].

이러한, 대차프레임은 차체와 승객하중에 의한 정적 하중과 운행 중 발생하는 진동 및 외부하중에 의하여 피로파손이 발 생하게 된다[17]. 따라서, 대차프레임의 설계 시 정적하중에 의한 구조적 안전성뿐만 아니라 반복적인 피로하중에 의한 강 도평가가 반드시 수행되어야 한다[18]. 일반적으로 복합재의 피로파손은 금속재의 피로파손과 달리 피로과정에서의 강성저 하가 발생하며, 반복하중에 의한 잔류강도가 저하됨에 따라 동적하중에 노출되는 구조물에 적용할 경우 피로특성에 대한 평가가 반드시 수행되어야 한다[19-20]. 또한, 대차프레임과 같이 인장-압축의 교번하중(alternating load)이 반복되는 구조 물에 복합재가 적용될 경우 압축 하중에 의한 적층 복합재의 균열열림현상(crack-tip open)과 층간분리(delamination)에 의해 금속재와는 달리 인장-인장 피로수명에 비해 인장-압축 피로 수명이 낮은 경향을 나타내게 된다[21]. 이에, 복합재 대차 프 레임의 경우 인장-압축 피로시험을 통해 적용 소재에 대한 피 로 특성을 파악하는 것이 중요한 선결 과제가 된다.

따라서, 본 연구에서는 철도차량 대차프레임의 경량화를 위
해 적용된 유리섬유/에폭시 4-매 주자직 적층 복합재료의 피 로특성 및 수명을 인장-압축 피로시험을 통하여 평가하였으며, 대차프레임의 피로강도 평가를 위해 요구되는 Goodman 선도 역시 도출하였다. 유리섬유/에폭시 4-매 주자직 적층 복합재의 인장-압축 피로시험은 응력비(R)를 -1로 적용하였고, 시험 주 파수는 $5 \mathrm{~Hz}$ 그리고 피로한도는 $10^{7}$ 사이클로 선정하였다. 이 때, 압축하중 시 발생할 수 있는 시험편의 좌굴을 방지하기 위해 좌굴방지지그(anti-buckling jig)를 고안하여 적용하였다. 또한, 기존 대차프레임에 일반적으로 적용되는 금속재 재질인 SM490과의 피로특성에 대한 비교 평가를 수행하였다.

\section{2. 복합재 대차 프레임 및 기계적 물성 평가}

\section{1 복합재 적용 경량화 대차 프레임}

현재 한국철도기술연구원에서 개발 중인 도시철도차량용 경량화 대차프레임은 외부 면재(outer skin)와 보강재 (reinforcement)에 4-매 주자직 적층 복합재(glass fiber/epoxy 4-harness woven laminate composite)가 적용 되었으며, 내부 심재에는 PVC 폼 코어(PVC foam core)가 적용되었다. 외부 면재와 보강재를 구성하는 유리섬유/에폭시 4-매 주자직 적 층 복합재는 경사(warp)와 위사(fill)가 4회 주기로 교차하는 형태로써, 경사방향의 높은 강도 특성을 갖으며, 단일방향 (uni-direction) 복합재료에 비하여 경사와 위사의 직각방향으 로 높은 상호 안정성과 균형적인 평면 특성을 갖는다[22].

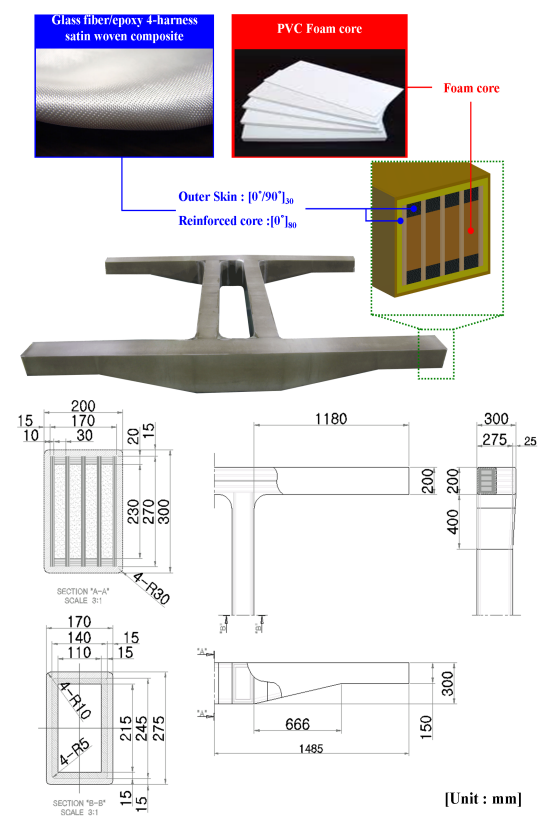

Fig. 1 Composite bogie frame manufactured using autoclave. 
복합재 대차프레임 제작은 볼스터와 사이드 프레임 형상을 갖는 PVC 폼 코어를 제작하고, 폼 코어 양면에 유리섬유/에폭 시 4-매 주자직 복합재를 경사방향으로 적층하여 보강재를 제 작한다. 이후, $80^{\circ} \mathrm{C}$ 의 온도와 $1.2 \mathrm{bar}$ 의 압력에서 2 시간정도 경 화하여 가접착한 후 경사, 위사 그리고 $\pm 45^{\circ}$ 방향으로 외부 면 재를 적층하고 오토클레이브 공법을 이용하여 $80^{\circ} \mathrm{C}, 120 \mathrm{C}^{\circ}$ 의 온도이력과 $6 \mathrm{bar}$ 의 압력을 적용하여 성형하였다. Fig. 1은 유리 섬유/에폭시 4-매 주자직 적층 복합재가 적용된 철도차량 경량 화 대차프레임의 형상을 나타낸다.

제작 완료된 복합재 대차프레임은 철도차량에서 요구되는 하중시험을 통하여 기존 금속재 대차프레임에 비해 비교적 낮 은 수준의 굽힘강성을 가짐을 확인하였다. 그러나, 기존 금속 재 대차프레임은 보수적인 과잉설계가 되었으며, 무게절감을 통한 경량화를 전혀 고려하지 않는 설계가 수행되었다. 따라 서, 복합재가 적용된 대차프레임의 경우 기존 금속재 대차프레 임에 비하여 낮은 굽힘 강성을 갖으나, 약 $60 \%$ 가량의 무게 절감 효과가 있어 에너지 효율 측면에서 장점을 보이고 있다. 또한, 복합재 대차프레임의 굽힘 강성 저하는 기존 금속재 대 차프레임에 사용되는 댐퍼와 같은 진동감쇠 효과를 갖도록 개 념설계 단계에서 인위적으로 의도한 결과이기도 하다.

\section{2 기계적 물성 평가}

대차프레임의 외부 면재와 보강재를 구성하는 유리섬유/에 폭시 복합재료의 인장-압축 피로시험을 수행하기 위하여 파손 강도 $(\mathrm{Su})$ 를 확인하였다. 이때, 외부 면재를 구성하는 복합재료 의 각 적층방향에 따른 피로특성을 확인하기 위해 위사, 경사 그리고 $\pm 45^{\circ}$ 방향의 시험편을 제작하고 인장, 압축에 대한 파 손강도를 확인하였다. 유리섬유/에폭시 4-매 주자직 적층 복합 재의 파손강도 확인을 위한 시험은 적층 복합재 인장, 압축 시험규정인 ASTM D 3039[23], ASTM D 3410[24]에 의거하 여 수행하였으며, 만능재료시험기(Instron-4484)를 사용하였다. Table 1은 적층 방향에 따른 유리섬유/에폭시 4-매 주자직 적 층 복합재의 기계적 물성을 보여준다.

Table 1 Mechanical properties of glass fiber/epoxy 4-hamess satin woven laminate composite

\begin{tabular}{c|c|c|c}
\hline \hline \multicolumn{2}{c|}{ Test Case } & Strength(MPa) & ${ }^{*}$ S.D(\%) \\
\hline \multirow{3}{*}{ Warp direction } & Tensile test & 636.06 & 0.95 \\
\cline { 2 - 4 } & Compressive test & 565.58 & 2.89 \\
\hline \multirow{2}{*}{ Fill direction } & Tensile test & 106.98 & 1.81 \\
\cline { 2 - 4 } & Compressive test & 217.00 & 0.41 \\
\hline \multirow{3}{*}{ $\pm 45^{\circ}$ direction } & Tensile test & 172.63 & 0.37 \\
\cline { 2 - 4 } & Compressive test & 162.34 & 0.44 \\
\hline \hline
\end{tabular}

\footnotetext{
* S.D : Standard deviation
}

\section{3. 인장-압축 피로시험}

\section{1 피로시험 장비 및 조건}

최근 적층 복합재에 대한 다양한 피로특성의 연구가 수행되 고 있으며, 특히 홀 노치(hole-notch)등과 같은 섬유 불연속 구 간의 피로수명 저하 예측에 대한 연구가 활발히 수행되고 있다 [25]. 그러나, 인장-압축 피로시험의 경우 압축 하중 시 발생하 는 시편의 좌굴 현상으로 인해 시험이 어렵고, 피로파손 모드 의 예측이 어려워 많은 연구가 수행되지 않고 있는 실정이다.

이에, 본 연구에서는 유리섬유/에폭시 4-매 주자직 적층 복 합재의 인장-압축 피로시험을 ASTM D 3479[26]와 ISO 13003[27] 규정을 참고하여 수행하였으며, 압축 하중 시 발생 하는 시편의 좌굴 방지를 위해 좌굴 방지 지그를 고안하여 적 용하였다. 이때, 응력비 $\left(\mathrm{R}=\sigma \min / \sigma_{\max }\right)$ 는 -1 로 설정하였고, 대차 프레임의 피로 수명 평가를 위한 Goodman 선도 역시 도출하 였다. 시험편 성형은 $0.25 \mathrm{~mm}$ 두께를 갖는 유리섬유/에폭시 4매 주자직 프리프레그(prepreg)를 적층하고 오토클레이브 (autoclave)를 사용하여 성형하였다. 이때, 시험편의 종류는 위 사방향, 경사방향 및 $\pm 45^{\circ}$ 방향을 각각 고려하여 제작하였다.

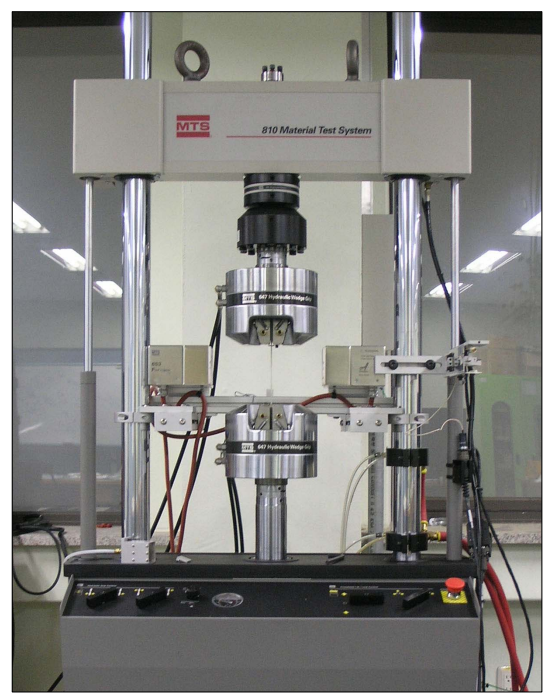

Fig. 2 Fatigue test instrument.

유리섬유/에폭시 4-매 주자직 적층 복합재의 인장-압축 피로 시험은 기계적 물성 시험을 통해 얻은 파손강도를 기준으로 65 20\% 범위 내에서 각 하중단계에 대해 5 개의 시험편을 시험 하였다. 이때, 시험 주파수는 반복하중에 의한 시험편 내부의 자체 온도상승을 무시할 수 있는 $5 \mathrm{~Hz}$ 로 선정하였으며[28], 피 로한도는 일반적인 대차프레임 소재에서 요구되는 피로수명인 200 만회 이상을 만족하는 $10^{7}$ 사이클로 선정하였다[29]. Fig. 2는 피로시험에 사용된 동적피로시험기(MTS 810)를 보여준다. 


\section{2 좌굴방지 지그}

적층 복합재료의 인장-압축피로 하중에서, 압축하중은 시편 에 층간분리와 균열 열림 현상을 발생시키며, 이는 인장하중에 의하여 확장되게 된다. 따라서, 이런 이유로 복합재에 대한 인 장-압축 피로는 일반적으로 금속재와는 달리 인장-인장 피로시 험에 비해 낮은 피로수명을 나타내게 된다. 또한, 압축하중에 의한 좌굴(buckling)이 발생하게 되며, 이로 인해 피로수명 평가 에 어려움이 있다[30]. 이에, Curtis[31], Bolick[32]는 인장-압축 피로시험 시 압축하중에 의한 좌굴을 방지하기 위하여 별도 의 좌굴방지지그를 고안하였다. 본 연구에서는 Curtis가 제안 한 좌굴방지지그를 수정 보완하여 제작하였다.

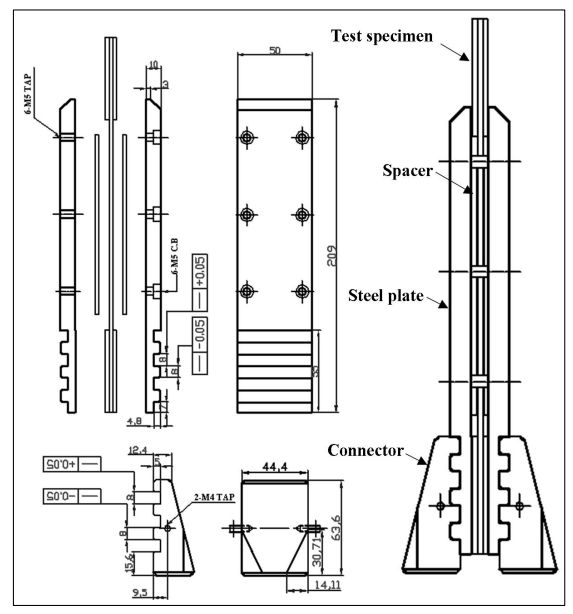

Fig. 3 Drawings of anti-buckling jig.

Fig. 3의 좌굴방지지그는 시험편의 양면을 지지하는 강재 플 레이트(steel plate), 시험장비와 지그의 연결을 위한 연결기 (connector), 시험편 탭의 두께를 고려한 스페이서(spacer)로 구 성된다. 이때, 시험편을 고정하는 강재 플레이트 하부는 슬롯가 공을 통하여 시험편의 미끌림을 방지하였다. 또한, 시험편과 스 페이서의 마찰을 최소화하기 위하여 접촉부에 폴리에스테르 필 름을 적용하였다.

본 연구에서 수정 보완된 좌굴방지지그의 좌굴유무를 검증 하기 위해 피로시험과 동일한 응력비 $(\mathrm{R}=-1)$ 와 주파수 $(5 \mathrm{~Hz})$ 에 서 시험편에 발생하는 변형률 측정하고 지그의 검증을 수행 하였다. 이때, 변형률 측정은 피로시험편 각 위치에서 발생하 는 변형률을 확인하기 위하여 상단(P1), 중간(P2) 그리고 하 단(P3)의 위치를 선정하여 접촉식 스트레인 게이지를 부착하 였다. 변형률 측정은 동적측정장비(DC-204R)를 사용하였으며, 초당 10 개의 데이터를 수집하였다. 좌굴방지지그 검증을 위한 시험결과 피로시험편의 각 측정 위치에서 발생하는 변형률이 서로 일치함으로 좌굴이 일어나지 않음을 확인하였다. Fig. 4 는 피로시험편 각 위치에서 발생하는 변형을 보여준다.

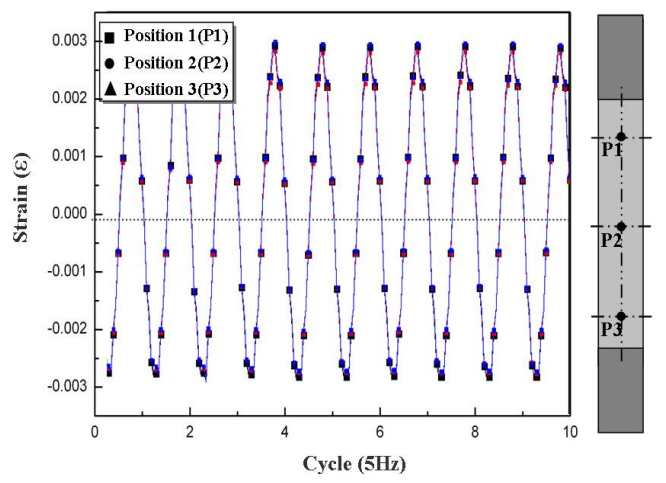

Fig. 4 Strain results of fatigue test specimen.

또한, 시편의 거동을 육안으로 확인하기 위해 고속카메라 (EoSence CL)를 사용하여 1000fps로 촬영하였다. 이때, 시편 과 좌굴방지지그 사이의 횡방향 간섭과 시편의 국부적인 좌 굴현상이 발생하지 않음을 확인하였다. Fig. 5는 육안검사를 위한 고속카메라 촬영 모습을 나타낸다.

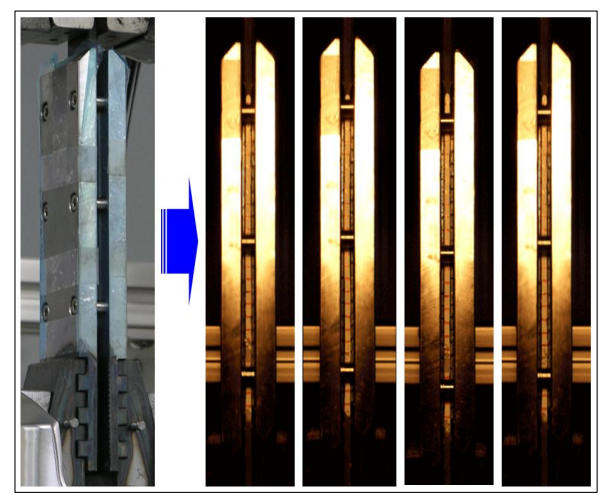

Fig. 5 The visual inspection of fatigue test specimen under tensioncompression loading using high-speed camera.

\section{4. 인장-압축 피로시험 결과 고찰}

\section{1 피로특성 평가 결과}

유리섬유/에폭시 4-매 주자직 복합재료의 적층 방향에 따른 인장-압축 피로시험은 5단계의 하중에 대해 수행하였다. 이때, 적층 복합재의 피로 특성을 평가하기 위해 기존 철도차량 대차 에 널리 적용되는 SM490에 대한 피로특성과 비교하였다. $\mathrm{SM} 490$ 의 피로특성은 참고문헌[33]을 통해 얻었으며, 이때 시험 조건은 일반적으로 금속재에 대해 많이 수행되는 응력비가 0.1 인 인장-인장 하중 하에서의 결과이다. 또한, 최대 응력에 따른 피로한도 비교는 대차프레임 피로시험 규정인 JIS E 4207[34]에 명시된 모재부와 용접부에 대해 각각 비교하였다. 
유리섬유/에폭시 4-매 주자직 적층 복합재와 SM490 금속재 의 S-N 선도를 하중비에 대해 Fig. 6과 같이 얻을 수 있었다. 이때, 각 하중단계에서 적층 복합재의 재현성이 우수함을 확인 하였다. 적층 복합재의 $10^{7}$ 사이클까지의 피로한도는 경사방향 시험편에서 $25 \%$, 위사방향과 \pm 45 방향 시험편에서는 $20 \%$ 가 각 각 확인되었다. 각 하중단계에서의 피로수명에서 복합재의 경사 방향과 위사방향은 SM490과 비슷한 결과를 나타냄을 확인하였 다. 이때, 적용 재료에 관계없이 대차프레임은 동일한 한계 설 계 치수를 가지므로, SM490 금속재에 비해 약 $1 / 3$ 의 무게를 갖 는 복합재 대차프레임의 피로특성(특히, 경사방향 복합재 적용 시)이 무게 대비 우수할 것으로 판단된다.

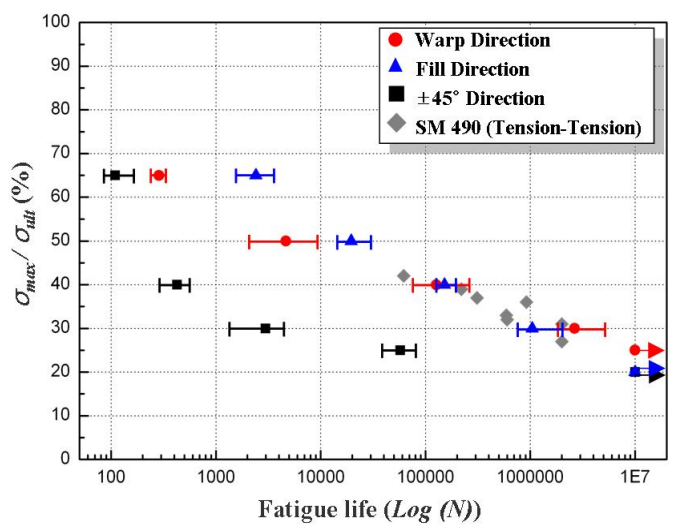

Fig. 6 Normalized stress ration vs fatigue life for glass fabric/epoxy 4-hamess woven laminate composite.

각 복합재의 적층 방향에 따른 기계적 물성의 차이를 고려 하여 Fig. 7과 같이 유리섬유/에폭시 4-매 주자직 적층 복합재 의 피로 시험을 통해 얻은 S-N 선도를 최대응력에 대해서도 나타내었다. 이때, 피로한도인 $10^{7}$ 사이클에서의 최대응력은 경 사방향은 $141.4 \mathrm{MPa}$, 위사방향은 $21.4 \mathrm{MPa}, \pm 45^{\circ}$ 방향은 $32.5 \mathrm{MP}$ 로서, 적층된 방향에 따른 파손강도 특성에 따라 차이가 나타 났다. 각 하중단계에서의 피로수명에서 경사방향을 갖는 복합재 시편이 SM490과 비슷한 결과를 보였으나, 인장-인장 하중이 가해진 SM490에 비해 인장-압축 하중이 가해진 적층 복합재가 더 우수한 피로 특성을 갖는 것으로 사료된다. 또한, 기존 금속 재 대차프레임의 경우 용접을 통해 제작되며, 이때 금속재 용 접에 의한 피로강도 저하가 발생하므로 모재부와 용접부의 피 로강도를 나누어 평가하게 된다. 금속재 대차프레임 피로시험규 정인 JIS E 4207에서 제시된 SM490의 피로한도에서의 강도값 이 모재부가 $155 \mathrm{MPa}$ 인 반면, 그라인딩 처리된 용접부에서는 $110 \mathrm{MPa}$, 그라인딩 처리되지 않은 용접부에서는 $70 \mathrm{MPa}$ 로 나타 난다. 반면, 적층 복합재의 경우 일체 성형이 가능하여 용접등 에 의한 피로특성 저하가 발생하지 않음으로 경사방향 적층 복 합재의 피로한도에서 강도값인 $141.4 \mathrm{MPa}$ 이 SM490 금속재의 용접부에 비하여 우수한 피로특성을 갖는 것으로 확인되었다.

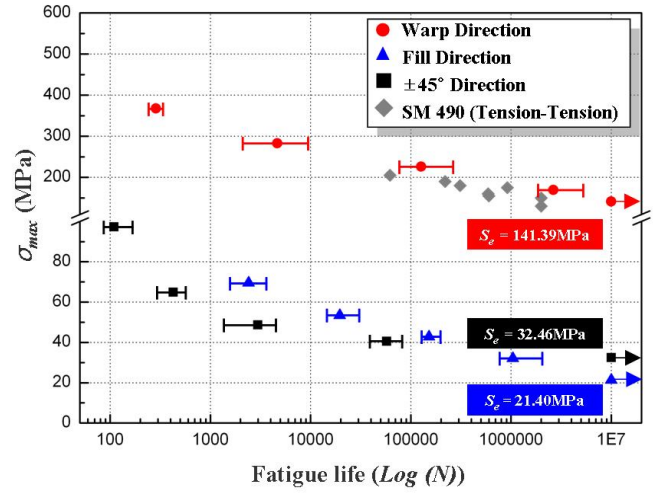

Fig. 7 Maximum stress vs fatigue life for glass fiber/epoxy 4-hamess satin woven laminate composite.

유리섬유/에폭시 4-매 주자직 인장-압축 피로시험을 통해 얻은 S-N 선도를 이용하여 피로특성을 평가하기 위한 Goodman 선도를 Fig. 8과 같이 나타냈다. 이때, Goodman 선도는 식 (1)에 의해 얻었으며, 평균응력 $\left(\sigma_{m}\right)$ 은 식(2), 응력진 폭 $\left(\sigma_{a}\right)$ 은 식(3)에 의해 각각 도출되었다. 여기서, $\sigma_{\max }$ 와 $\sigma_{\min }$ 는 각각 최대 및 최소 주응력을 의미한다.

이때, 경사방향 적층 복합재가 SM490의 모재부에 비하여 높은 파손강도를 갖는 반면, 피로한도가 낮아 두 선도가 서 로 교차함을 확인하였다. 또한, SM490의 용접부에 비하여 경사방향 적층 복합재에서 높은 파손강도와 피로한도를 나타 냄을 확인하였다.

$$
\begin{aligned}
& \frac{\sigma_{a}}{S_{e}}+\frac{\sigma_{m}}{S_{u}}=1 \\
& \sigma_{m}=\frac{\left(\sigma_{\max }+\sigma_{\min }\right)}{2} \\
& \sigma_{a}=\frac{\left(\sigma_{\max }-\sigma_{\min }\right)}{2}
\end{aligned}
$$

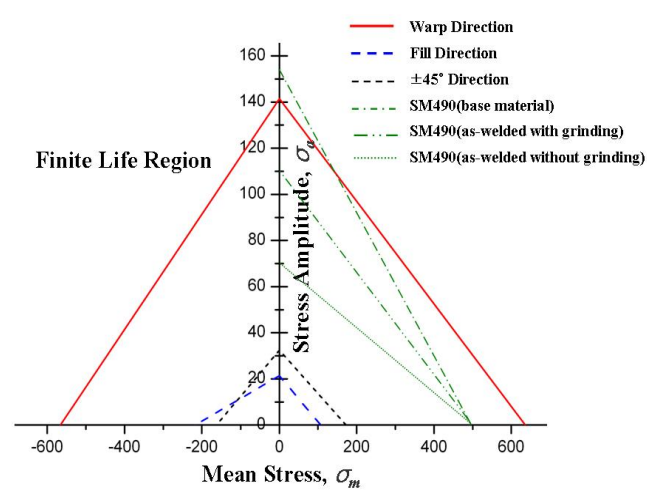

Fig. 8 Goodman diagram for glass fiber/epoxy 4-hamess satin woven laminate composite \& SM490. 


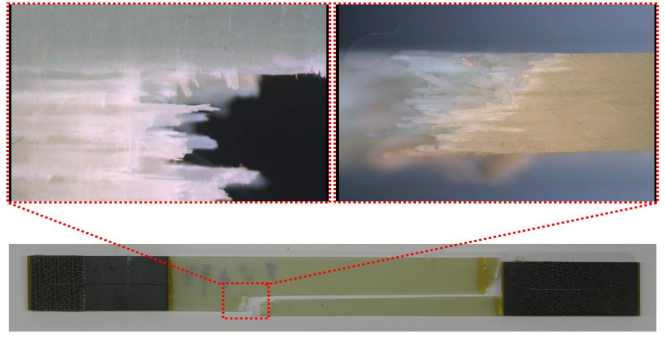

(a) Stacking sequence of warp-direction

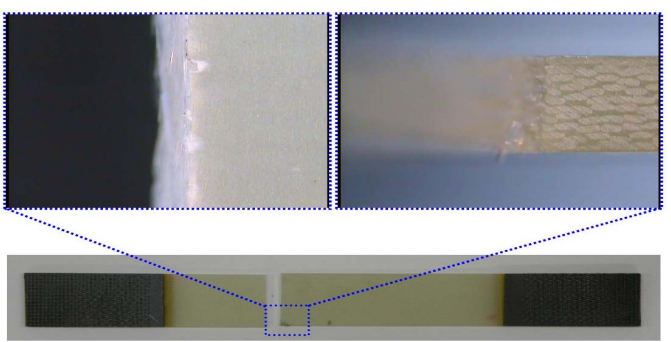

(b) Stacking sequence of fill-direction

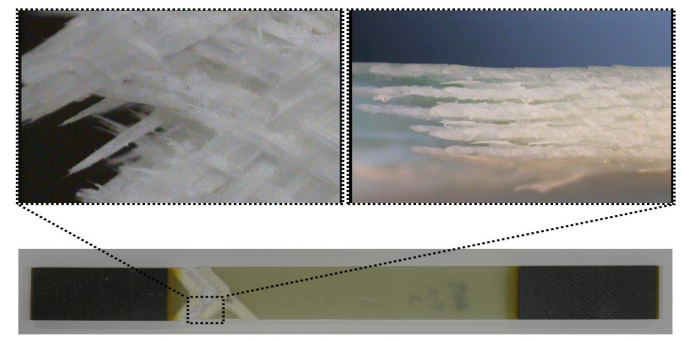

(c) Stacking sequence of $\pm 45^{\circ}$-direction

Fig. 9 Fatigue failure modes of glass fiber/epoxy 4-hamess satin woven laminate composite.

Fig. 9는 각 적층 방향에 따른 유리섬유/에폭시 4-매 주자 직 복합재의 전형적인 피로파손 모습을 보여준다. 피로하중 에 의한 유리섬유/에폭시 4-매 주자직 적층 복합재료의 파손 은 기지균열(matrix cracking), 섬유파손(fiber breakage), 섬유 와 모재간의 분리(debonding), 층간분리 등의 형태가 확인되 었다. 시험편의 파손부위는 시험편 중앙부분 및 탭부분에서 전체적으로 발생하였으며, 각 파손 위치에 따른 피로수명 결 과에 대한 오차가 적음을 확인하였다.

\section{2 피로시험 고찰}

본 연구에서는 철도차량 대차프레임의 경량화를 위해 적용 된 유리섬유/에폭시 4-매 주자직 적층 복합재의 인장-압축 피 로시험을 수행한 결과, 경사방향 적층 복합재의 피로특성이 기존 금속재 대차프레임 재질인 SM490과 비슷함을 확인 하 였으며, SM490에 비하여 낮은 비중을 갖는 복합재에서 무게 당 피로특성이 우수한 것으로 판단된다. 또한, 용접을 통하여
제작되는 기존 금속재 대차프레임의 경우 그라인딩 처리된 용 접부에서 $110 \mathrm{MPa}$ 와 그라인딩 처리되지 않은 용접부에서 $70 \mathrm{MPa}$ 의 피로한도에서의 강도값을 갖고 있으나 용접등과 같 은 별도의 피로특성 저하가 발생하지 않는 복합재의 경우 경 사방향에서 $141.4 \mathrm{MPa}$ 로 우수한 피로특성을 나타냄을 확인하 였다. 이는 복합재 대차프레임에 유리섬유/에폭시 4-매 주자직 적층 복합재 적용시에 하중이 높게 발생하는 방향에 경사방향 을 고려하여 피로강도를 만족할 수 있을 것으로 판단된다. 또 한, 금속재인 SM490에 비해 적층 복합재의 비중이 약 $23 \%$ 정도이며, 이로 인해 대차프레임의 경량화 효율을 크게 높일 수 있을 것으로 사료된다.

\section{5. 결 론}

본 연구는 철도차량용 대차프레임의 경량화를 위하여 적 용된 유리섬유/에폭시 4-매 주자직 적층 복합재료의 적층 방 향에 따른 인장-압축 피로시험을 수행하였으며, 다음과 같은 결론을 도출하였다.

1) 유리섬유/에폭시 4-매 주자직 적층 복합재의 인장-압축 피로시험 수행 시 압축하중에 따른 시험편의 좌굴을 방지 하기 위하여 좌굴방지지그(anti-buckling jig)를 적용하였 으며, 인장-압축 피로시험 시에 좌굴이 발생하지 않음을 검증을 통하여 확인하였다.

2) 인장-압축 피로시험 결과 응력비에 따른 유리섬유/에폭시 4-매 주자직 적층 복합재의 피로특성은 경사방향과 위사 방향에서 SM490과 비슷한 피로특성을 나타냄을 확인하 였으며, 최대응력에 따른 피로특성의 경우 경사방향 적층 복합재에서 SM490와 비슷한 피로특성을 나타냄을 확인 하였다. 이는, 금속재에 비하여 약 $1 / 4$ 의 비중을 갖는 적층 복합재에서 무게 대비 우수한 피로특성을 갖고 있음을 확인하였다.

3) 유리섬유/에폭시 4-매 주자직 적층 복합재의 인장-압축 피로 시험을 통하여 Goodman 선도를 도출하였으며, 이를 통해 차량운행시 발생하는 다양한 하중조건을 갖는 복합재 대차 프레임의 피로강도 평가가 가능할 것으로 사료된다.

4) 유리섬유/에폭시 4-매 주자직 적층 복합재를 철도차량 대차프레임에 적용할 경우 주 구조물(main structure)에 피로특성이 우수한 경사방향 적층 복합재를 사용함으로써, 기존 금속재와 같은 피로강도를 만족하면서 경량화 효과를 얻을 수 있게 된다.

\section{후 기}

본 연구는 지식경제부 산업기술연구회에서 지원한 일반연구 
사업 “복합소재의 철도차량 적용에 관한 연구”가 지원하는 연구 과제로 수행된 것이며, 지원에 대해 진심으로 감사드립니다.

\section{참고문헌}

1) N. Y. Jung, and S. B. Lee, "Light Weight by Application of Aluminum Honeycomb Sandwich Panels in End Door of Rolling Stock," Autumn Conference of The Korean Society of Machine Tool Engineers Conference, 1997, pp. 284-291.

2) J. S. Koo, and H. J. Cho, "A Method to estimate the Weight-reduction of Hybrid Bodyshells by Material Substitution," The Korean Society for Railway, Vol. 9, No. 6, 2006, pp. 635-643.

3) T. S. Kwon, H. Y. Lee, and H. Shin, "Introduction to the material substitution design method for the weight reduction of rolling stock carbody," Autumn Conference of The Korean Society for Railway Conference, 2003, pp. 446-454.

4) K. B. Shin, D. H. Koo, S. H. Han, K. J. Park, “ A Study on Material Selection of the Carbody Structure of Korean Tilting Train eXpress(TTX) through the Verification of Design Requirements," Journal of the Korean Society for Railway, Vol. 7, No. 2, 2004, pp. 77-84.

5) K. B. Shin, B. J. Ryu, J. Y. Lee, S. J. Lee, S. H. Jo, "Evaluation of the Structural Integrity of a Sandwich Composite Train Roof Structure," Autumn Conference of The Korean Society for Railway Conference, 2005, pp. 46-51.

6) K. B. Shin, B. J. Ryu, J. Y. Lee, S. J. Lee, and S. H. Jo, "A Study on Manufacturing Technology and Evaluation of the Structural Integrity of a Sandwich Composite Train Roof Structure," The Korean Society for Railway, Vol. 9, No. 1, 2006, pp. 46-51.

7) K. B. Shin, and S. H. Han, "Evaluation of Static Stability of Hybrid Carbody Structures of Korean Tilting Train eXpress Including Degradation Effects of Composite Materials under Ground Environments," The Korean Society for Mechanical Engineers, Vol. 28, No. 6, 2005, pp. 807-815.

8) Y. S. Lee, J. H. Kim, H. C. Lee, K. N. Kil and B. J. Park, "A Study the Application of 3D Sandwich Composite Structures to the Double-deck Light Train Carbody,” Journal of the Korean Society for Railway, Vol. 3, No. 2, 2000, pp. 92-99.

9) G. Belingardi, M. P. Cavtorta and R. Duella, "Material Characterization of a Composite Foam Sandwich for the
Front Structure of a High Speed Train,” Composite Structures, Vol. 61, 2003, pp. 13-25.

10) A. M. Harte, J. F. Mcnamara and I. D. Roddy , "A Multilevel Approach to the Optimization of a Composite Light rail Vehicle Bodyshell,“ Composite Structures, Vol. 63, 2004, pp. 447-453.

11) J. S. Kim, J. C. Jeong, S. H. Cho, and S. I. Seo, "Analytical and Experimental Studies on the Natural Frequency of a Composite Train Carbody,” The Korean Society for Mechanical Engineers, Vol. 30, No. 4, 2006, pp. 473-480.

12) H. Y. Ko, K. B. Shin, J. C. Jeong, 2009, "A Study on the Comparison of Structural Performance Test and Analysis for Design Verification of Bimodal Tram Vehicle made of Sandwich Composites," The Korean Society for Railway, Vol. 12, No. 4, pp. 518-525.

13) H. Y. Ko, K. B. Shin, S. H. Cho, D. H. Kim, 2008, “An Evaluation of Structural Integrity and Crashworthiness of Automatic Guideway Transit (AGT) Vehicle made of Sandwich Composites," The Korean Society of Composite Materials, Vol. 21, No. 5, pp. 15-22.

14) B. H. Park, N. P. Kim, J. S. Kim, and K. Y. Lee, "Bogie Frame Design Considering Fatigue Strength and Minimize Weight," Autumn Conference of The Korean Society for Railway, 2004, pp. 131-136.

15) I. S. Yun, S. T. Kwon, J. S. Sun, N. J. Myung, W. H. Chung, T. S. Son, K. K. Kim, and S. C. Kim, "Integrity Evaluation of Bogie Frame by Ultrasonic Fractography Analysis," The Korean Society for Railway, Vol. 3, No. 2, 2000, pp. 112-118.

16) Maurin. L, J. Boussoir, S. Rougeault, M. Bugaud, P. Ferdinand, A. G. Landrot, Y. H. Grunevald, and T. Chauvin, "FBG-based Smart Composite Bogie for Railway Applications," IEEE Conference, Vol. 1, 2002, pp. 91-94.

17) S. R. Lee, H. J. Lee, S. W. Han, J. Y. Kim, J. H. Cha, J. Y. Kang, C. K. Park, "Fatigue Design and Fatigue Strength Evaluation of Bogie Frame," Spring Conference of The Korean Society for Railway Conference, 2000, pp. 234-241.

18) W. J. Kim, S. Y. Song, G. S. Park, H. S. Park, "Evalution of static and fatigue strength applying European standard for the bogie frame of Diesel Multiple Unit," Autumn Conference of The Korean Society for Railway Conference, 2007, pp. 797-804.

19) R. J. Ming-hwa, J. M. Hsu, D. G. Hwang, 1990, "Fatigue Degradation in Centrally Notched Quasi-Isotropic Laminates," Composite Materials, Vol. 24, pp. 823-838.

20) S. S. Jang, 2007, "A Reliability Analysis on the Fatigue 
Life Prediction in Carbon/Epoxy Composite Material,” The Korean Society of Industrial Application, Vol. 10, No. 3, pp. 143-147.

21) E. K. Gamstedt, and B. A. Sjoegren, "Micromechanisms in tension-compression fatigue of composite laminates containing transverse plies," Composites Science and Technology, Vol. 59, 1999, pp. 167-178.

22) J. H. Byun, "Prediction of Engineering Constants for Plain and 8-Harness Satin Woven Composites," The Korean Society for Mechanical Engineers, Vol. 21, No. 11, 1997, pp. 1757-1764.

23) American Society for Testing Materials : ASTM D 3039, Standard Test Method for Tensile Properties of Polymer Matrix Composite Materials.

24) American Society for Testing Materials : ASTM D 3410, Standard Test Method for Compressive Properties of Polymer Matrix Composite Materials with Unsupported Gage Section by Shear Loading.

25) S. Y. Kim, Y. S. Kim, H. W. Kwon, J.H. Choi, J. M. Koo, and C. S. Seok, "Prediction of Fatigue Life for Holenotched Weave CFRP Plate," Spring Conference of The Korean Society of Composite Materials, 2010, pp. 128-133.

26) American Society for Testing Materials : ASTM D 3479, Standard Test Method for Tension-Tension Fatigue of Polymer Matrix Composite Materials.

27) International Organization for Standardization : ISO 13003, Fibre reinforced plastics Determination of fatigue properties under cyclic loading conditions.

28) Hwang, W. and han, K. S., "Fatigue of Composites Fatigue Modulus Concept and Life Prediction,” Journal of Composite Materials, Vol. 20, 1986, pp. 154-165.

29) J. S. Park, C. S. Seok, J. M. Koo, J. H. S, B. C. Goo, "Fatigue Characteristics of SM490A Welded Joints for Bogie Frame," Journal of Korea Society for Precision Engineering, Vol. 21, 2004, pp. 146-153.

30) S. Mall, D.W. Katwyk, R.L. Bolick, A.D. Kelkar, D.C. Davis, "Tension-.compression fatigue behavior of a H-VARTM manufactured unnotched and notched carbon/epoxy composite," Composite Structures, Vol. 90, 2009, pp. 201-207.

31) H. Bryan., "Fatigue Composite Materials,“ CRC Press, 2003.

32) Bolick. R. L, "A comparative study of unstitched, stitched, and Z-pinned plain woven composites under fatigue loading," $\mathrm{PhD}$ dissertation, North Carolina Agricultural and Technical State University, 2005.

33) B. C. Goo, and S. Y. Yang, "Fatigue Life Prediction Considering Residual Stress Relaxation,” International
Congress of Theoretical and Applied Mechanics, 2004.

34) Japanese Industrial Standard : JIS E 4702, Truck frames for railway rolling stock. 